\title{
温度和光周期协同作用对蒙古栎幼苗春季物候的影响
}

\author{
胡明新 ${ }^{1,2,3}$, 周广胜 ${ }^{1,3,4, *}$, 吕晓敏 ${ }^{1,3}$, 王思琪 ${ }^{1}$, 张世雅 ${ }^{5}$ \\ 1 中国气象科学研究院固城生态与农业气象试验站, 北京 100081 \\ 2 中国气象局公共气象服务中心, 北京 100081 \\ 3 郑州大学地球系统科学与技术研究院生态气象联合实验室, 郑州 450001 \\ 4 南京信息工程大学气象灾害预报预警与评估协同创新中心，南京 210044 \\ 5 太原理工大学矿业工程学院测绘系, 太原 030024
}

摘要:植物物候对气候变化非常敏感,但关于物候对不同气候因子协同作用的响应机制仍不清楚。为此,以蒙古栋为研究对象, 针对蒙古栋物候的主要影响因子温度和光周期,利用大型人工气候室,模拟研究了温度与光周期协同作用 (对照、增温 $1.5^{\circ} \mathrm{C} 、$ 增 温 $2.0^{\circ} \mathrm{C}$, 不同光周期 $\left(10 \mathrm{~h} 、 14 \mathrm{~h} 、 18 \mathrm{~h}\right.$ ) 及其协同作用 (对照处理、增温 $1.5^{\circ} \mathrm{C} \times 18 \mathrm{~h} 、$ 增温 $1.5^{\circ} \mathrm{C} \times 10 \mathrm{~h} 、$ 增温 $2.0^{\circ} \mathrm{C} \times 18 \mathrm{~h} 、$ 增温 $2.0^{\circ} \mathrm{C}$ $\times 10 \mathrm{~h}))$ 对蒙古栋春季物候的影响与机制。结果表明:(1)相同水分条件下,不同升温程度对蒙古栎幼苗春季物候的影响不同。 温升 $1.5^{\circ} \mathrm{C}$ 促进蒙古栋幼苗春季物候 (芽膨大期、芽开放期、展叶始期和展叶盛期) 提前; 而温升 $2.0^{\circ} \mathrm{C}$ 则对不同春季物候的影响 不同,表现为促进芽休眠解除和芽开放,但抑制叶片展开。(2) 相同水分条件下,不同光周期对蒙古柇幼苗不同春季物候的影 响存在差异。长光周期对蒙古栎幼苗展叶盛期影响最大,短光周期对芽膨大期影响最大,但均表现为抑制作用。(3)相同水分 条件下,温度升高与光周期增加协同作用有助于促进蒙古栋幼苗春季物候提前, 但温度升高与光周期缩短协同作用则对春季物 候有抑制作用。(4)蒙古栋幼苗春季物候变化与前期气候胁迫程度存在显著正相关, 表明前期气候因子也是物候变化的重要 影响因子。研究结果丰富了蒙古栎物候响应多气候因子协同作用的认知,有助于促进物候模型的完善。

关键词: 蒙古栋;幼苗;物候;增温;光周期;协同作用

\section{Interactive effects of different warming and changing photoperiod on spring phenology of Quercus mongolicus seedlings}

\author{
HU Mingxin ${ }^{1,2,3}$, ZHOU Guangsheng ${ }^{1,3,4, *}$, LÜ Xiaomin ${ }^{1,3}$, WANG Siqi ${ }^{1}$, ZHANG Shiya ${ }^{5}$ \\ 1 Gucheng Experimental Station of Ecological and Agricultural Meteorology, Chinese Academy of Meteorological Sciences, Beijing 100081, China \\ 2 Public Weather Service Center, China Meterological Administration, Beijing 100081, China \\ 3 College of Earth Science \& Technology, Zhengzhou University, Zhengzhou 450001, China \\ 4 Collaborative Innovation Center on Forecast and Evaluation of Meteorological Disasters, Nanj̈ing University of Information Science and Technology, Nanj̈ing \\ 210044, China \\ 5 Department of Geomatics, College of Mining Engineering, Taiyuan University of Technology, Taiyuan 030024, China
}

\begin{abstract}
Plant phenology is very sensitive to climate change. However, the interactive effects of different climatic variables on plant phenology are still unclear. Thus, taking Quercus mongolica as the research object, we studied the interactive effects of different warming and changing photoperiod (control treatment ( CK), $1.5^{\circ} \mathrm{C}$ warming, $2.0^{\circ} \mathrm{C}$ warming; different photoperiods $(10 \mathrm{~h}, 14 \mathrm{~h}$, and $18 \mathrm{~h})$; CK, $1.5^{\circ} \mathrm{C}$ warming $\times 18 \mathrm{~h}, 1.5^{\circ} \mathrm{C}$ warming $\times 10 \mathrm{~h}, 2.0^{\circ} \mathrm{C}$ warming $\times 18 \mathrm{~h}, 2.0^{\circ} \mathrm{C}$

基金项目: 国家重点研发计划(2018YFA0606103); 国家自然科学基金(41501047,41571175); 中国气象科学研究院基本科研业务费专项经费共 同资助

收稿日期:2020-04-22; 网络出版日期:2021-01-27

* 通讯作者 Corresponding author.E-mail: zhougs@ cma.gov.cn
\end{abstract}

http ://www.ecologica.cn 
warming $\times 10 \mathrm{~h})$ on the spring phenology of Quercus mongolica seedlings based on the experimental data of large artificial climate simulation chamber in the context of global warming. The results are as follows: (1) Under the same water condition, different warming had different effects on the spring phenology of Quercus mongolica seedlings. The $1.5^{\circ} \mathrm{C}$ warming promoted the spring phenology, including bud swelling ( BS), bud opening ( BO), first full leaf ( F1), and 50\% leaves unfolded $(\mathrm{LU})$ stages. The influence of $2.0^{\circ} \mathrm{C}$ warming on different spring phenology was different. $2.0^{\circ} \mathrm{C}$ warming promoted the release of bud dormancy and leaf BO, but inhibited the leaf extension. (2) Under the same water condition, the effect of different photoperiods on the spring phenology of Quercus mongolica seedlings was different. The long photoperiod had the greatest influence on the 50\% LU stage, while the short photoperiod had the greatest influence on the BS stage, but they all showed negative effects. (3) Under the same water condition, prolonging photoperiod under warming treatments was helpful to promote the spring phenology of Quercus mongolica seedlings, including the BO, F1 and 50\% LU stages. While shortening of photoperiod under warming treatments inhibited the spring phenology of Quercus mongolica seedlings, including the BS, F1 and 50\% LU stages. (4) There was a significant correlation between spring phenological changes of Quercus mongolica seedlings and previous climate stress, implying that the previous climatic variables should be the significantly controlling factors to phenological changes. The results could enrich the cognition of the interactive effects of multiple climatic variables in Quercus mongolica phenology, and are helpful to promote plant phenology simulation.

Key Words : Quercus mongolica; seedling; phenology; warming; photoperiod; interaction

气候变暖已经成为不争的事实, 并对生态系统产生了重大的影响 ${ }^{[1]}$ 。《巴黎协定》提出, 将全球平均温度 升幅控制在较前工业化时期高 $2.0^{\circ} \mathrm{C}$ 以内, 并努力把温度升幅限定在 $1.5^{\circ} \mathrm{C}$ 内, 以减小气候变化带来的风险和 影响 ${ }^{[2]}$ 。相较于气候增暖 $2.0^{\circ} \mathrm{C}$ 而言, 将增暖控制在 $1.5^{\circ} \mathrm{C}$ 以内能在一定程度上减小气候变化影响的风险。 一旦全球平均升温达到 $2.0^{\circ} \mathrm{C}$, 将使生态系统处于严重的风险之中 ${ }^{[3]}$ 。因此, 将全球温升限制在 $1.5^{\circ} \mathrm{C}$ 内逐渐 成为全球共识。

植物物候对气候变化非常敏感, 春季物候作为生长季的开始, 对生态系统的结构与功能具有重要的影 响 ${ }^{[4-6]}$ 。研究表明, 温度升高引起植物春季物候提前 ${ }^{[7-11]}$ 。温度和光周期被认为是影响温带木本植物春季物 候的关键因素 ${ }^{[12-14]}$ 。气候变暖导致的春季物候提前意味着春季物候将发生在较短的光周期条件下,然而现 有研究主要集中在温度升高对植物春季物候的影响方面,关于光周期变化及其与温度升高协同作用的影响仍 不清楚 ${ }^{[15]}$ 。

蒙古栋 ( Quercus mongolica) 又名蒙栋、柞树, 属壳斗科、栎属, 是中国东北地区天然次生林的重要组成树 种 ${ }^{[16-17]}$ 。气候变暖影响蒙古栎幼苗的生长特性和生理生态特征 ${ }^{[18-21]}$, 特别是未来气候变暖将使蒙古栎的地 理分布范围扩大, 成为中国东北森林的最主要树种 ${ }^{[22-23]}$ 。蒙古栎是喜光树种, 光照条件不但影响其形态、光 合和生物量分配 ${ }^{[24-26]}$, 也明显影响其物候期。研究表明, 延长光照时间能够加速蒙古柇的生理过程, 从而促 进物候期提前 ${ }^{[27]}$ 。但温度和光周期协同作用对蒙古栋春季物候的影响与机制仍不清楚。

本研究以 1 年生蒙古栎幼苗为研究对象, 通过开展不同增温 (对照、 $1.5^{\circ} \mathrm{C} 、 2.0^{\circ} \mathrm{C}$ )、光周期 $(10 \mathrm{~h} 、 14 \mathrm{~h} 、$ $18 \mathrm{~h}$ ) 及其协同作用 (增温 $1.5^{\circ} \mathrm{C} \times 18 \mathrm{~h}$ 、增温 $1.5^{\circ} \mathrm{C} \times 10 \mathrm{~h}$ 、增温 $2.0^{\circ} \mathrm{C} \times 18 \mathrm{~h}$ 、增温 $2.0^{\circ} \mathrm{C} \times 10 \mathrm{~h}$ ) 的大型人工气候室 模拟控制实验, 研究蒙古栋幼苗春季物候期对不同增温与光周期协同作用的响应机制, 以增进气候变化对蒙 古栋物候影响的理解,为蒙古栋物候模拟提供依据。

\section{1 实验材料和设计}

\section{1 实验材料}

实验所用蒙古栋 ( Querus mongolica) 幼苗产自黑龙江省齐齐哈尔市拜泉县林场, 苗龄为 1 年。选择生长 状况基本一致的幼苗, 分别移栽至口径为 $20 \mathrm{~cm}$ 、高为 $20 \mathrm{~cm}$ 的塑料盆中, 每盆 1 株。栽培用土为产苗当地土 
壤, 土壤类型为黑土。3 月中旬将来自于产地的蒙古栋幼苗装土处理, 在大型人工气候室模拟生长地气候条 件下生长 $15 \mathrm{~d}$ 后,于 4 月初开展不同增温与光周期协同作用影响的大型人工气候室模拟实验。

\section{2 实验设计}

实验地点位于中国气象局固城生态与农业气象试验站 $\left(39^{\circ} 08^{\prime} \mathrm{N}, 115^{\circ} 40^{\prime} \mathrm{E}\right.$, 海拔 $\left.15.2 \mathrm{~m}\right)$, 蒙古栎幼苗春 季物候模拟实验时间为 2019 年 4 月至 7 月。模拟实验控制的环境要素为温度和光周期,均设置 3 个水平,共 9 个处理,每个处理 4 次重复。

\subsection{1 增温控制实验}

利用大型人工气候室控制环境温度, 设置 3 个温度水平,其中对照温度是黑龙江省齐齐哈尔市拜泉县蒙 古栋幼苗生长季相应月份近 30 年的平均气温 (表 1), 增温处理是在对照温度基础上分别增温 $1.5^{\circ} \mathrm{C}(\mathrm{T} 1$ ) 和 $2.0^{\circ} \mathrm{C}(\mathrm{T} 2)$ 。

\subsection{2 光周期控制实验}

通过人工气候室内三组钠灯的开关时间设置 $10 \mathrm{~h} 、 14 \mathrm{~h}$ 和 $18 \mathrm{~h}$ 共 3 种光周期, 其中对照组 $14 \mathrm{~h}$ 为拜泉县 蒙古栋生长季的平均日照长度, $10 \mathrm{~h}(-4 \mathrm{~h})$ 为短光周期处理 $(\mathrm{S}), 18 \mathrm{~h}(+4 \mathrm{~h})$ 为长光周期处理 $(\mathrm{L})$ 。

\subsection{3 温度与光周期协同作用控制实验}

在大型人工气候室分别设置对照处理 ( $\mathrm{CK}$, 即保持生长地生长温度和光周期) 、增温 $1.5^{\circ} \mathrm{C}$ 和长光周期处 理 $(\mathrm{T} 1 \mathrm{~L}) 、$ 增温 $1.5^{\circ} \mathrm{C}$ 和短光周期处理 $(\mathrm{T} 1 \mathrm{~S}) 、$ 增温 $2.0^{\circ} \mathrm{C}$ 和长光周期处理 $(\mathrm{T} 2 \mathrm{~L}) 、$ 增温 $2.0^{\circ} \mathrm{C}$ 和短光周期处理 (T2S) 共 5 个处理的增温与光周期协同作用控制实验。对照处理 (CK) 的温度和光周期为拜泉县近 30 年蒙 古栋生长季的平均气温和平均日照长度 $14 \mathrm{~h}$ 。

模拟实验的大型人工气候室内空气相对湿度和 $\mathrm{CO}_{2}$ 浓度均保持一致。空气相对湿度为 $(50 \pm 5) \%$, 由人 工气候室自动控制; $\mathrm{CO}_{2}$ 浓度为正常条件下大气 $\mathrm{CO}_{2}$ 浓度, 约为 $(400 \pm 20) \mu \mathrm{mol} / \mathrm{mol}$ 。将拜泉县近 30 年各月平 均降水量换算成灌溉量 (表 1), 每 3 天对幼苗浇水一次, 以维持适宜的土壤湿度, 确保幼苗存活。

表 1 实验期间模拟降水量和对照组月平均气温

Table 1 Simulated precipitation and monthly average temperature of control group during the experiment

\begin{tabular}{ccc||ccc}
\hline $\begin{array}{c}\text { 月份 } \\
\text { Month }\end{array}$ & $\begin{array}{c}\text { 月平均气温 } \\
\text { Monthly average } \\
\text { temperature } /{ }^{\circ} \mathrm{C}\end{array}$ & $\begin{array}{c}\text { 月降水量 } \\
\text { Monthly } \\
\text { precipitation } / \mathrm{mm}\end{array}$ & $\begin{array}{c}\text { 月份 } \\
\text { Month }\end{array}$ & $\begin{array}{c}\text { 月平均气温 } \\
\text { Monthly average } \\
\text { temperature } /{ }^{\circ} \mathrm{C}\end{array}$ & $\begin{array}{c}\text { 月降水量 } \\
\text { Monthly } \\
\text { precipitation } / \mathrm{mm}\end{array}$ \\
\hline 4 & 5.65 & 19.51 & 6 & 19.96 & 87.04 \\
5 & 14.02 & 37.64 & 7 & 22.33 & 155.24 \\
\hline
\end{tabular}

气温和降水数据来源于中国气象数据网

\section{2 研究方法}

\section{1 物候观测}

按照《中国物候观测方法》 ${ }^{288}$ 进行蒙古栋物候观测, 观测的春季物候包括芽膨大期、芽开放期、展叶始期 和展叶盛期。每 2 天观测一次, 观测时间在 14:00 左右,记录蒙古栎到达目标物候的日期。将日期转化为儒 略日 (Julian days), 即年序列累积日数 (Day of year, DOY)。当观测植株 $1-2$ 个小枝上芽鳞片开始分开, 侧面 显露淡色的线形或角形, 认为植株达到芽膨大期。若芽的鳞片裂开, 上部出现新鲜颜色的尖端或形成新的苍 片而伸长, 则记录为芽开放期。展叶始期和展叶盛期分别以枝条上初次出现小叶和 50\%枝条上的小叶完全 展开为判断标准。

\section{2 物候温度敏感性}

敏感性指系统在受到与气候有关的刺激时受影响的程度,包括不利影响和有利影响 ${ }^{[29]}$ 。物候温度敏感 性指温度每增加 $1^{\circ} \mathrm{C}$, 植物物候事件改变的天数 ${ }^{[30]}$, 计算如下:

$$
S_{\text {phen }}=\left(E_{\text {warm }}-E_{\text {cont }}\right) /\left(T_{\text {warm }}-T_{\text {cont }}\right)
$$


式中, $S_{\mathrm{phen}}$ 为物候温度敏感性 $\left(\mathrm{d} /{ }^{\circ} \mathrm{C}\right), E_{\mathrm{warm}}$ 为增温处理植物物候事件发生的日序; $E_{\mathrm{cont}}$ 为对照处理植物物候事 件发生的日序; $T_{\text {warm }}$ 为增温处理的空气温度 $\left({ }^{\circ} \mathrm{C}\right) ; T_{\text {cont }}$ 为对照处理的空气温度 $\left({ }^{\circ} \mathrm{C}\right)$ 。

2.3 数据分析方法

采用单因素方差分析 (one-way ANOVA) 和双因素方差分析 (two-way ANOVA)方法,分析不同温升和光周 期及其协同作用下蒙古栋春季不同物候期和物候阶段的差异; 采用相关性分析方法, 分析各物候期之间的相 关关系,所用软件为 SPSS 21.0(SPSS Inc., Chicago, IL, USA)。利用 Microsoft Excel 2013 进行回归分析,探讨 蒙古栋幼苗不同物候期之间的相关性。使用 OriginPro 2016 和 Microsoft Excel 2013 完成绘图。

\section{3 结果与分析}

3.1 蒙古栋幼苗春季物候期对温度、光周期及其协同作用的响应

实验各处理的蒙古柇幼苗芽膨大期发生时间见表 2。芽膨大期整体处于 120.0-127.0 d 之间。增温处理 使蒙古栋幼苗芽膨大期显著提前 (图 1) , 增温 $1.5^{\circ} \mathrm{C}$ 和 $2.0^{\circ} \mathrm{C}$ 分别提前 $2.0 \mathrm{~d}$ 和 $4.5 \mathrm{~d}$ 。长光周期对芽膨大期影 响不显著,但短光周期显著推迟了芽膨大期,约推迟 $1.5 \mathrm{~d}$ 。增温 $1.5^{\circ} \mathrm{C}$ 和长光周期协同作用导致蒙古栎幼苗 芽膨大期提前但不显著, 增温 $2.0^{\circ} \mathrm{C}$ 和长光周期协同作用使芽膨大期提前 $4.5 \mathrm{~d}$; 短光周期条件下, 增温 $1.5^{\circ} \mathrm{C}$ 和增温 $2.0^{\circ} \mathrm{C}$ 分别使芽膨大期推迟 $2.0 \mathrm{~d}$ 和 $2.5 \mathrm{~d}$ 。因此,增温 $1.5^{\circ} \mathrm{C}$ 或 $2.0^{\circ} \mathrm{C}$ 有利于蒙古栋幼苗提前解除芽休 眠, 短光周期对解除芽休眠起着抑制作用; 增温和长光周期协同作用能够促进芽休眠解除, 而增温和短光周期 协同作用则抑制芽休眠解除。

表 2 蒙古栎幼苗春季物候实验结果

Table 2 Spring phenology of Quercus mongolica seedlings during the simulated experiments

\begin{tabular}{|c|c|c|c|c|}
\hline $\begin{array}{c}\text { 处理 } \\
\text { Treatments }\end{array}$ & $\begin{array}{c}\text { 芽膨大期 } \\
\text { Bud swelling }\end{array}$ & $\begin{array}{l}\text { 芽开放期 } \\
\text { Bud opening }\end{array}$ & $\begin{array}{l}\text { 展叶始期 } \\
\text { First full leaf }\end{array}$ & $\begin{array}{c}\text { 展叶盛期 } \\
50 \% \text { Leaves unfolded }\end{array}$ \\
\hline CK & 124.5 & 130.0 & 134.0 & 136.5 \\
\hline $\mathrm{T} 1$ & 122.5 & 128.5 & 132.0 & 135.5 \\
\hline $\mathrm{T} 2$ & 120.0 & 128.5 & 134.5 & 138.0 \\
\hline $\mathrm{L}$ & 124.0 & 130.0 & 134.0 & 139.0 \\
\hline $\mathrm{S}$ & 126.0 & 129.5 & 133.0 & 135.5 \\
\hline $\mathrm{T} 1 \mathrm{~L}$ & 123.0 & 127.5 & 131.0 & 134.0 \\
\hline $\mathrm{T} 1 \mathrm{~S}$ & 126.5 & 130.5 & 136.5 & 140.5 \\
\hline $\mathrm{T} 2 \mathrm{~L}$ & 121.5 & 127.0 & 130.5 & 131.0 \\
\hline $\mathrm{T} 2 \mathrm{~S}$ & 127.0 & 132.0 & 139.0 & 141.0 \\
\hline
\end{tabular}

$\mathrm{CK}$ : 对照处理, control treatments; $\mathrm{T} 1$ : 增温 $1.5^{\circ} \mathrm{C}$ 处理, $1.5^{\circ} \mathrm{C}$ warming treatment; $\mathrm{T} 2$ : 增温 $2.0^{\circ} \mathrm{C}$ 处理, $2.0^{\circ} \mathrm{C}$ warming treatment; $\mathrm{L}$ : 长光周期 处理, long photoperiod treatment; $\mathrm{S}$ : 短光周期处理, short photoperiod treatment; T1 L: 增温 $1.5^{\circ} \mathrm{C}$ 和长光周期处理, $1.5^{\circ} \mathrm{C}$ warming and prolonging photoperiod treatment; T1S: 增温 $1.5^{\circ} \mathrm{C}$ 和缩光周期处理, $1.5^{\circ} \mathrm{C}$ warming and shortening photoperiod treatment; $\mathrm{T} 2 \mathrm{~L}$ : 增温 $2.0^{\circ} \mathrm{C}$ 和长光周期处理, $2.0^{\circ} \mathrm{C}$ warming and prolonging photoperiod treatment; T1S: 增温 $2.0^{\circ} \mathrm{C}$ 和短光周期处理, $2.0^{\circ} \mathrm{C}$ warming and shortening photoperiod treatment

实验各处理蒙古栋幼苗芽开放期发生时间见表 2。芽开放期整体处于 127.0-132.0 d 之间。增温使蒙古 栎幼苗芽开放期显著提前 (图 1)。增温 $1.5^{\circ} \mathrm{C}$ 和增温 $2.0^{\circ} \mathrm{C}$ 均使芽开放期提前 $2.5 \mathrm{~d}$; 延长或缩短光周期对芽 开放期影响不显著。长光周期和增温协同作用均使蒙古栋幼苗芽开放期显著提前。其中, 长光周期和增温 $1.5^{\circ} \mathrm{C}$ 协同作用使芽开放期提前 $2.5 \mathrm{~d}$, 长光周期和增温 $2.0^{\circ} \mathrm{C}$ 协同作用使芽开放期提前 $3.0 \mathrm{~d}$ 。短光周期条件 下,增温 $2.0^{\circ} \mathrm{C}$ 使芽开放期推迟 $2.0 \mathrm{~d}$, 但增温 $1.5^{\circ} \mathrm{C}$ 对芽开放期推迟作用不显著。

蒙古柇幼苗展叶始期整体处于 130.5-139.0 d 之间 (表 2)。增温 $1.5^{\circ} \mathrm{C}$ 使蒙古栎幼苗的展叶始期提前 $2.0 \mathrm{~d}$, 但增温 $2.0^{\circ} \mathrm{C}$ 的影响不显著 (图 1)。延长或缩短光周期对蒙古栋幼苗的展叶始期影响均不显著。长光 周期和增温协同作用均使蒙古柇幼苗展叶始期提前, 其中增温 $1.5^{\circ} \mathrm{C}$ 和增温 $2.0^{\circ} \mathrm{C}$ 分别使展叶始期提前 $3.0 \mathrm{~d}$ 

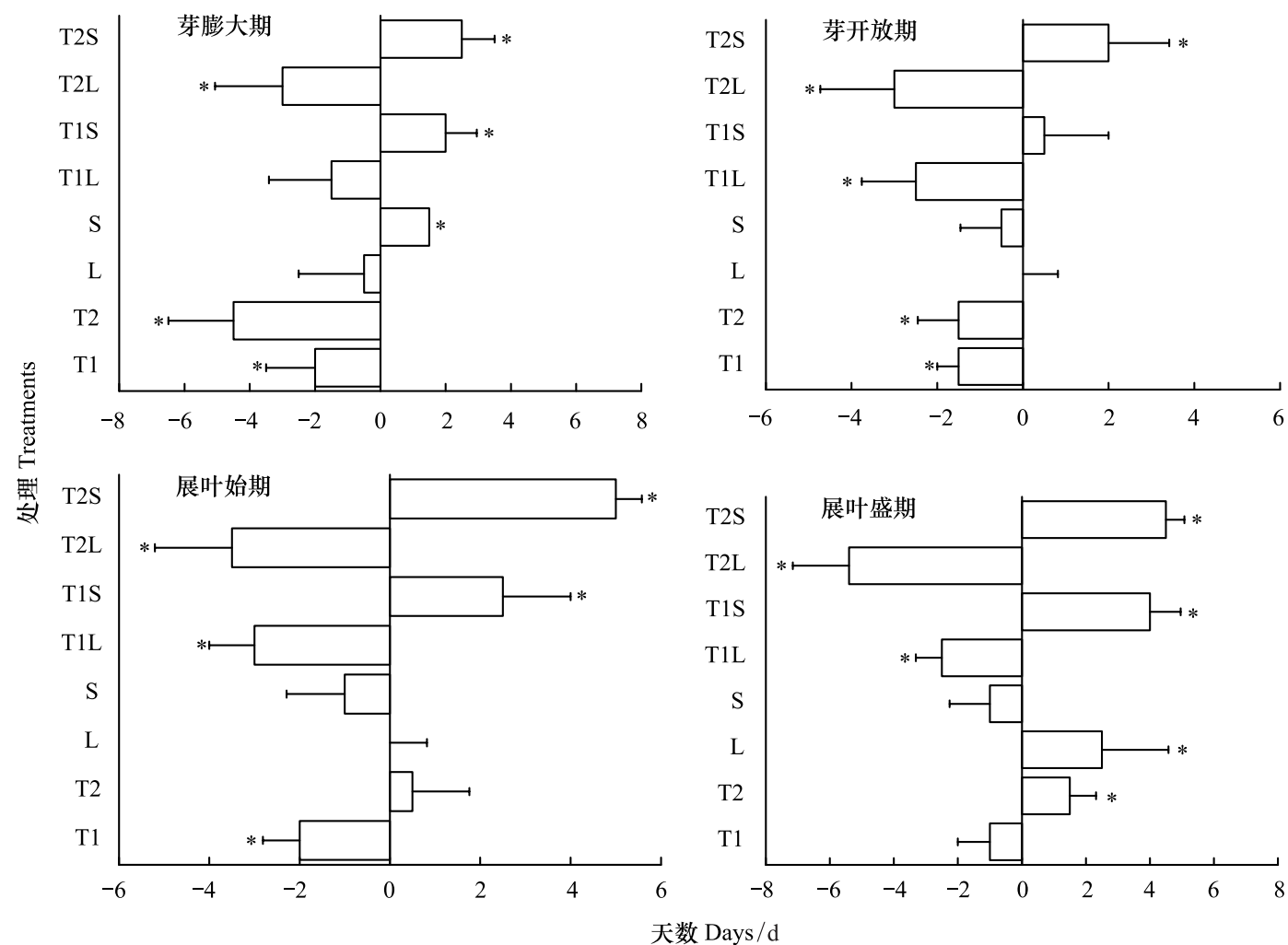

图 1 增温、光周期及其协同作用对蒙古栎幼苗芽膨大期、芽开放期、展叶始期和展叶盛期的影响 (平均值士标准误差)

Fig.1 Effects of warming, photoperiod and their interactions on bud swelling stage, bud opening stage, first full leaf stage and $50 \%$ leaves unfolded stage of Quercus mongolica Seedlings (Mean \pm Standard Error)

正值代表与对照 $\mathrm{CK}$ 相比推迟的天数, 负值代表与对照相比提前的天数; * 代表与对照相比差异显著 $(P<0.05)$; CK：对照处理, control treatments; $\mathrm{T} 1$ : 增温 $1.5^{\circ} \mathrm{C}$ 处理, $1.5^{\circ} \mathrm{C}$ warming treatment; $\mathrm{T} 2$ : 增温 $2.0^{\circ} \mathrm{C}$ 处理, $2.0^{\circ} \mathrm{C}$ warming treatment; $\mathrm{L}$ : 长光周期处理, long photoperiod treatment; $\mathrm{S}$ : 短光周期处理, short photoperiod treatment; $\mathrm{T} 1 \mathrm{~L}$ : 增温 $1.5^{\circ} \mathrm{C}$ 和长光周期处理, $1.5^{\circ} \mathrm{C}$ warming and prolonging photoperiod treatment; T1S: 增温 $1.5^{\circ} \mathrm{C}$ 和缩光周期处理, $1.5^{\circ} \mathrm{C}$ warming and shortening photoperiod treatment; T2L: 增温 $2.0^{\circ} \mathrm{C}$ 和长光周期处理, $2.0^{\circ} \mathrm{C}$ warming and prolonging photoperiod treatment; T1S: 增温 $2.0^{\circ} \mathrm{C}$ 和短光周期处理, $2.0^{\circ} \mathrm{C}$ warming and shortening photoperiod treatment

和 $3.5 \mathrm{~d}$ 。短光周期和增温协同作用则均导致蒙古栎幼苗展叶始期延迟,其中增温 $1.5^{\circ} \mathrm{C}$ 和增温 $2.0^{\circ} \mathrm{C}$ 分别使 展叶始期推迟 $2.5 \mathrm{~d}$ 和 $5.0 \mathrm{~d}$ 。

蒙古栋幼苗展叶盛期整体处于 131.0-141.0 d 之间 (表 2)。增温处理对蒙古栋幼苗展叶盛期有显著影 响 (图 1) ,增温 $1.5^{\circ} \mathrm{C}$ 使展叶盛期显著提前 $1.0 \mathrm{~d}$, 而增温 $2.0^{\circ} \mathrm{C}$ 则导致展叶盛期显著推迟 $1.5 \mathrm{~d}$ 。长光周期使蒙 古栋幼苗展叶盛期显著推迟 $2.5 \mathrm{~d}$, 而短光周期的影响不显著。长光周期和增温协同作用均使蒙古栋幼苗展 叶盛期显著提前,其中增温 $1.5^{\circ} \mathrm{C}$ 和增温 $2.0^{\circ} \mathrm{C}$ 分别使展叶盛期提前 $2.5 \mathrm{~d}$ 和 $5.4 \mathrm{~d}$ 。短光周期和增温协同作用 对蒙古栋幼苗展叶盛期影响显著,其中增温 $1.5^{\circ} \mathrm{C}$ 和增温 $2.0^{\circ} \mathrm{C}$ 分别使展叶盛期推迟 $4.0 \mathrm{~d}$ 和 $4.5 \mathrm{~d}$ 。

3.2 蒙古栋幼苗各春季物候持续时间对温度与光周期协同作用的响应

温度、光周期及其协同作用均没有显著改变蒙古栋幼苗芽膨大期一芽开放期的持续时间 (图 2)。但增温 $2.0^{\circ} \mathrm{C}$ 使芽开放期-展叶始期的持续时间显著延长 $2.0 \mathrm{~d}$ 。短光周期条件下增温 $1.5^{\circ} \mathrm{C}$ 和增温 $2.0^{\circ} \mathrm{C}$ 使芽开放期展叶始期的持续时间分别延长 $2.0 \mathrm{~d}$ 和 $3.0 \mathrm{~d}$; 长光周期及其与增温 $2.0^{\circ} \mathrm{C}$ 协同作用分别使蒙古栎幼苗展叶始 期-展叶盛期的持续时间延长 $2.5 \mathrm{~d}$ 和 $2.0 \mathrm{~d}$,但增温 $1.5^{\circ} \mathrm{C}$ 和长光周期协同作用的影响不显著。

3.3 蒙古栋幼苗不同春季物候期的温度敏感性

增温与长光周期协同作用下, 蒙古栋幼苗春季物候的温度敏感性均为负值, 表明温度升高使春季物候提 前 (图 3)。增温与短光周期协同作用下, 蒙古栋幼苗春季物候的温度敏感性均为正值, 即在温升条件下缩短 


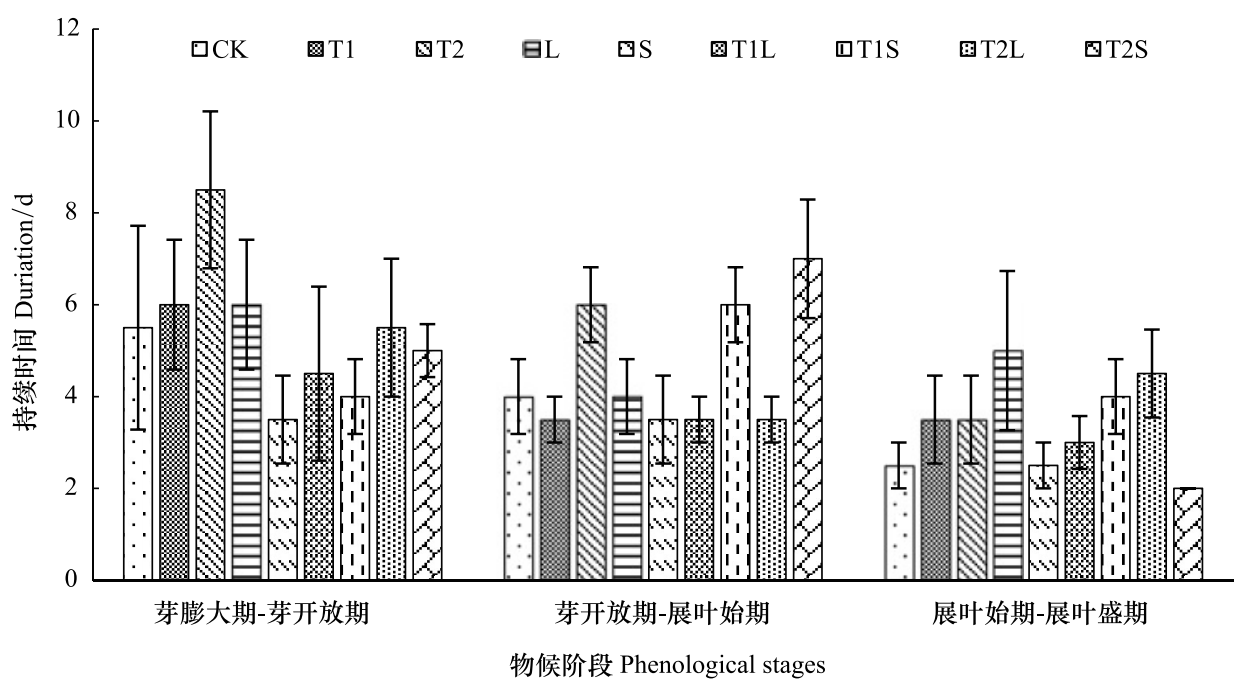

图 2 增温、光周期及其协同作用对蒙古栋幼苗各物候阶段持续时间的影响 (平均值土标准误差)

Fig.2 Effects of warming, photoperiod and their interactions on the duration of each phenological stage of Quercus mongolica Seedlings $($ Mean \pm Standard Error $)$

光周期将导致蒙古栋幼苗春季物候推迟。增温 $2.0^{\circ} \mathrm{C}$ 条 件下,随着物候期的推进, 蒙古柇幼苗的物候响应方式 发生改变, 表现为展叶前的芽膨大期和芽开放期提前, 展叶后的展叶始期和展叶盛期推迟。

3.4 蒙古柇幼苗不同春季物候期之间的相互关系

蒙古柇幼苗芽膨大期、芽开放期、展叶始期和展叶 盛期之间呈显著相关性 (表 3)。其中,芽膨大期与芽开 放期、芽膨大期与展叶始期、芽开放期与展叶始期、芽开 放期与展叶盛期、展叶始期与展叶盛期之间均在 0.01 水平上呈显著正相关,芽膨大期与展叶盛期之间在 0.05 水平上呈显著正相关。

不同处理下各春季物候期与前期物候期呈显著的 线性正相关 (图 4、表 4), 表明物候与前期温度和光周 期呈显著正相关, 尤其是芽开放期与展叶始期、展叶始 期与展叶盛期之间的相关性非常显著。

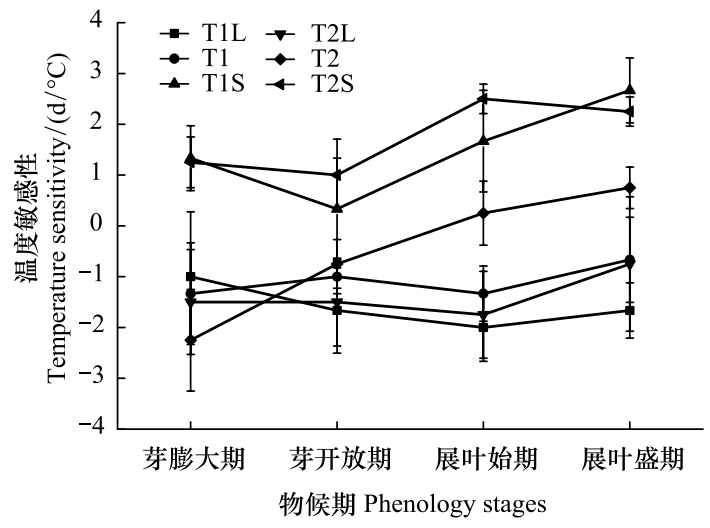

图 3 蒙古栎幼苗春季物候的温度敏感性

Fig. 3 Temperature sensitivity of spring phenology of Quercus mongolica seedlings

表 3 蒙古栋不同春季物候期之间的相关性

Table 3 Correlation between different spring phenological stages of Quercus mongolica

\begin{tabular}{|c|c|c|c|c|}
\hline 物候期 & 芽膨大期 & 芽开放期 & 展叶始期 & 展叶盛期 \\
\hline Phenological stage & Bud swelling & Bud opening & First full leaf & $50 \%$ Leaves unfolded \\
\hline 芽膨大期 Bud swelling & 1.000 & & & \\
\hline 芽开放期 Bud opening & $0.612^{* * *}$ & 1.000 & & \\
\hline 展叶始期 First full leaf & $0.491^{* * *}$ & $0.812^{* *}$ & 1.000 & \\
\hline 展叶盛期 50\% Leaves unfolded & $0.414^{*}$ & $0.716^{* *}$ & $0.857^{* *}$ & 1.000 \\
\hline
\end{tabular}

$*$ 和 $* *$ 分别代表在 $P<0.05$ 和 $P<0.01$ 水平( 双侧) 上显著相关 

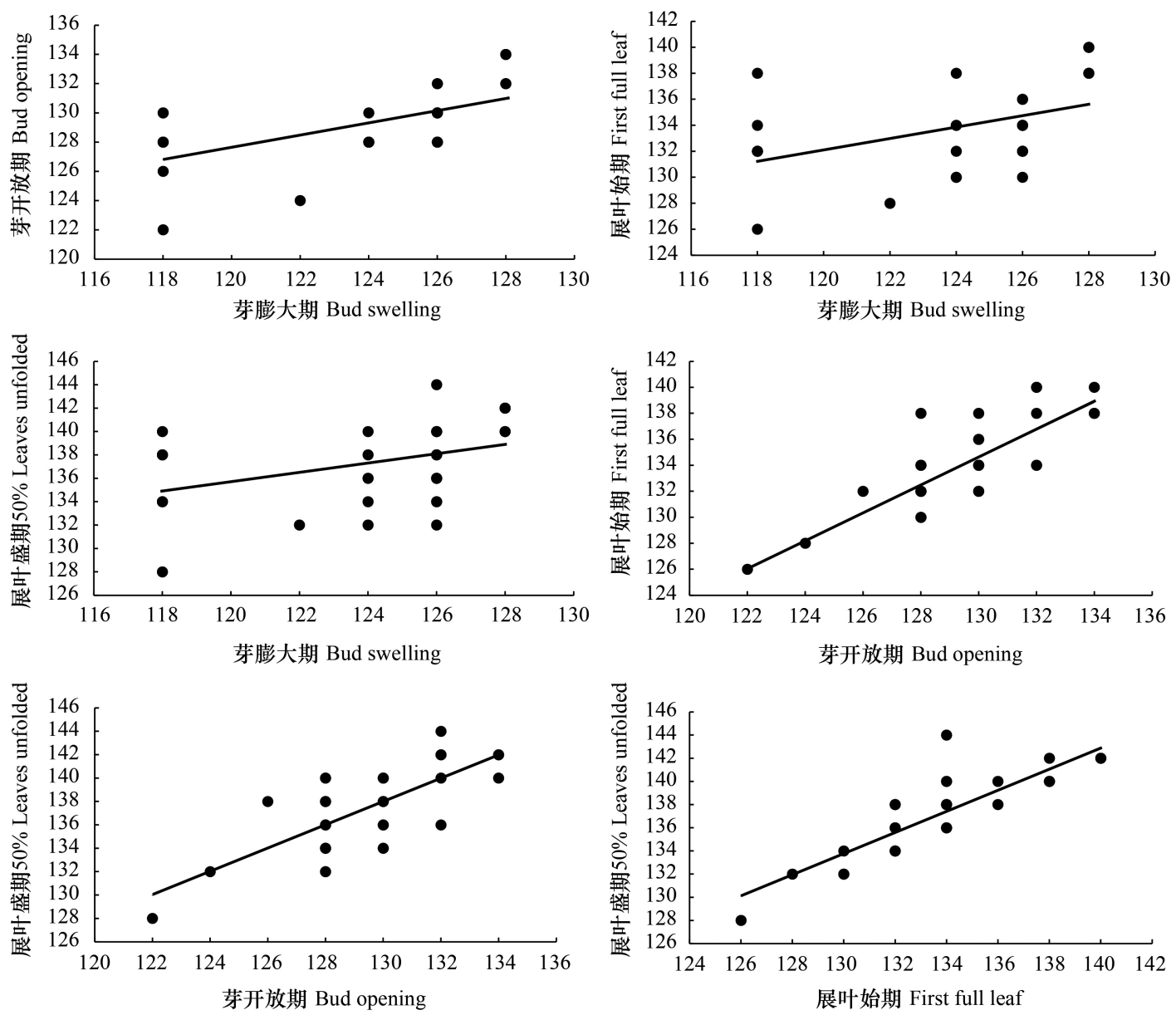

图 4 不同处理下蒙古栎幼苗各春季物候期之间的相关性

Fig.4 Relationship between spring phenological stages of Quercus mongolica seedlings under different treatments

表 4 不同春季物候期与前期物候期的相关性

Table 4 Relationship between phenological stage and its previous phenological stage

\begin{tabular}{|c|c|c|c|c|}
\hline $\begin{array}{l}\text { 物候期 } \\
\text { Phenological stage }\end{array}$ & $\begin{array}{l}\text { 拟合方程 } \\
\text { Fitting equation }\end{array}$ & $n$ & $R^{2}$ & $P$ \\
\hline $\begin{array}{l}\text { 芽膨大期-芽开放期 } \\
\text { Bud swelling-Bud opening }\end{array}$ & $B O=0.419 B S+77.323$ & 36 & 0.375 & 0.000 \\
\hline $\begin{array}{l}\text { 芽膨大期-展叶始期 } \\
\text { Bud swelling-First full leaf }\end{array}$ & $F 1=0.441 B S+79.237$ & 36 & 0.241 & 0.002 \\
\hline $\begin{array}{l}\text { 芽膨大期-展叶盛期 } \\
\text { Bud swelling-50\% Leaves unfolded }\end{array}$ & $L U=0.394 B S+88.424$ & 36 & 0.171 & 0.012 \\
\hline $\begin{array}{l}\text { 芽开放期-展叶始期 } \\
\text { Bud opening-First full leaf }\end{array}$ & $F 1=1.064 B O-3.736$ & 36 & 0.659 & 0.000 \\
\hline $\begin{array}{l}\text { 芽开放期-展叶盛期 } \\
\text { Bud opening-50\% Leaves unfolded }\end{array}$ & $L U=0.994 B O+8.774$ & 36 & 0.512 & 0.000 \\
\hline $\begin{array}{l}\text { 展叶始期-展叶盛期 } \\
\text { First full leaf- } 50 \% \text { Leaves unfolded }\end{array}$ & $L U=0.908 F 1+15.723$ & 36 & 0.735 & 0.000 \\
\hline
\end{tabular}

$B S$ : 芽膨大期, Bud swelling; BO: 芽开放期, Bud opening; F1: 展叶始期, First full leaf; $L U$ : 展叶盛期, 50\% Leaves unfolded

\section{4 讨论}

本研究表明,增温改变了蒙古栎幼苗的春季物候,且不同物候阶段对增温的响应方式和敏感程度不同。 
长期物候观测资料表明,不同增温条件下亚高山高寒草甸植物不同开花阶段物候的提前程度不同,温度增加 $(0.4 \pm 0.1)^{\circ} \mathrm{C} / 10 \mathrm{a}$ 使始花期提前 $(3.3 \pm 0.24) \mathrm{d} / 10 \mathrm{a}$ 、末花期提前 $(1.5 \pm 0.42) \mathrm{d} / 10 \mathrm{a}^{[31]}$ 。模拟增温实验也表明， 川西高山草甸优势植物的不同物候阶段对增温的响应方式和敏感性不同 ${ }^{[32]}$ 。植物发育是一个连续的过程, 早期发育阶段对后期发育具有一定的限制作用 ${ }^{[33]}$ 。因此,植物物候对温度变化的响应不仅与环境条件有关, 也与植物本身的生物学条件有关。本研究从蒙古标幼苗芽休眠解除后的第一个物候开始, 连续观测从芽膨大 期到展叶盛期的整个春季物候过程, 以准确理解蒙古栋幼苗春季物候对不同气候因子变化及其协同作用的响 应特征。

本研究发现,蒙古栋幼苗的春季物候对增温 $1.5^{\circ} \mathrm{C}$ 和增温 $2.0^{\circ} \mathrm{C}$ 的响应方式和敏感程度不同。增温 $1.5^{\circ} \mathrm{C}$ 在一定程度上促进了蒙古栋春季物候,但增温 $2.0^{\circ} \mathrm{C}$ 则抑制叶片展开,表明适宜的增温可以促进蒙古栎春季的 生长发育。当然, 完全理解温度等气候因子变化对物候期的影响机理仍需在充分理解植物内部生理生态机制 的基础上开展更深人的研究 ${ }^{[34-36]}$ 。

落叶木本植物春季芽萌发受温度影响的同时,也受到光周期的影响 ${ }^{[37-38]}$ 。气候变暖导致春季物候提前, 意味着春季物候将发生在较短的光周期条件下。低温和短光周期将延缓植物芽的萌发, 减小霜冻的风险, 而 温度升高则会促进芽的萌发 ${ }^{[39-40]}$ 。研究表明,植物物候的温度敏感性受光周期调控。光周期可以通过调整 木本植物物候积温需求和冷激需求的非线性关系, 进而调整其春季物候的发生时间, 以达到最优的生长策 略 ${ }^{[15]}$ 。最近研究发现, 植物叶片的温度敏感性在过去几十年间显著降低 ${ }^{[41]}$, 叶片温度敏感性的降低可能与 光周期有关 ${ }^{[42-43]}$ 。本研究表明,增温与短光周期协同作用抑制了蒙古柇的春季物候, 因此已有研究可能低估 了气候变暖对春季物候的提前作用。当然, 本研究还只是蒙古栋一个物种的研究结果, 关于光周期与温度协 同作用的物候调控机理仍需进一步研究。

气候变化对蒙古栋幼苗物候的影响复杂, 本研究仅基于一年的模拟实验资料分析了增温、光周期及其协 同作用对蒙古栋春季物候的影响, 没有考虑前期低温春化作用、其他气候因子以及生物学特性的影响。因此, 未来仍需开展更多因子协同作用、更长时间的模拟实验研究,完善蒙古柇物候对气候变化响应的理解。

\section{5 结论}

本研究基于大型人工气候室模拟实验资料分析研究了增温、光周期及其协同作用对蒙古栎幼苗春季物候 的影响, 主要结论如下:

(1) 不同增温幅度对蒙古栋幼苗春季物候的影响不同。温升 $1.5^{\circ} \mathrm{C}$ 促进春季物候 ( 芽膨大期、芽开放期、 展叶始期和展叶盛期) 提前, 温升 $2.0^{\circ} \mathrm{C}$ 尽管仍促进芽休眠解除和芽开放,但抑制叶片展开。

(2) 光周期长短对蒙古栎幼苗不同春季物候期的作用不同。长光周期对展叶盛期影响最大,而短光周期 对芽膨大期影响最大,但均表现为抑制作用。

(3) 增温环境下光周期增加促进蒙古柇幼苗春季物候提前, 而光周期缩短则抑制蒙古栎幼苗的春季 物候。

(4) 增温与光周期协同作用影响蒙古栋幼苗春季物候的持续时间。不同增温、增温 $2.0^{\circ} \mathrm{C}$ 与短光周期协 同作用均使芽开放期-展叶始期持续时间延长, 长光周期、增温 $2.0^{\circ} \mathrm{C}$ 与长光周期协同作用均使展叶始期-展叶 盛期持续时间延长。

(5) 物候变化与前期气候胁迫呈显著正相关,表明在物候模型发展时需要考虑前期环境因子的影响。

(6) 光周期可以调控蒙古栋春季物候的温度敏感性。增温条件下缩短光周期将使蒙古栋幼苗春季物候 的温度敏感性由负值变为正值,即增温与缩短光周期协同作用使蒙古栋幼苗春季物候由提前变为推迟。

\section{参考文献 (References)：}

[ 1 ] IPCC. Climate Change 2014: Synthesis Report. Contribution of Working Groups I, II and III to the Fifth Assessment Report of the Intergovernmental Panel on Climate Change. Geneva, Switzerland: Intergovernmental Panel on Climate Change, 2014: 151-151. 
[ 2 ] United Nations Framework Convention on Climate Change (UNFCCC). Adoption of the Paris Agreement, Decision 1/CP. 21. 2015.

[ 3 ] 翟盘茂, 余荣, 周佰铨, 陈阳, 郭建平, 卢燕宇. $1.5^{\circ} \mathrm{C}$ 增暖对全球和区域影响的研究进展. 气候变化研究进展, $2017,13(5)$ : $465-472$.

[4] 陆佩玲, 于强, 贺庆棠. 植物物候对气候变化的响应. 生态学报, 2006, 26(3): 923-929.

[ 5 ] Hulme P E. Contrasting impacts of climate-driven flowering phenology on changes in alien and native plant species distributions. New Phytologist, $2011,189(1): 272-281$.

[ 6 ] Polgar C A, Primack R B. 温带森林展叶物候学. 生物多样性, 2013, 21(1): 111-116.

[ 7 ] Ge Q S, Wang H J, Rutishauser T, Dai J H. Phenological response to climate change in China: a meta-analysis. Global Change Biology, 2015, 21 (1) : 265-274.

[ 8 ] Li Y, Wang L R, Zhu G R, Fang W C, Cao K, Chen C W, Wang X W, Wang X L. Phenological response of peach to climate change exhibits a relatively dramatic trend in China, 1983-2012. Scientia Horticulturae, 2016, 209: 192-200.

[ 9 ] Menzel A, Sparks T H, Estrella N, Koch E, Aasa A, Ahas R, Alm-Kübler K, Bissolli P, Braslavská O, Briede A, Chmielewski F M, Crepinsek Z, Curnel Y, Dahl Å, Defila C, Donnelly A, Filella Y, Jatczak K, Måge F, Mestre A, Nordli Ø, Peñuelas J, PIRINEN Pentti, R, Remišová V, Scheifinger H, Striz M, Susnik A, van Vliet A J H, Wielgolaski F E, Zach S, Zust A. European phenological response to climate change matches the warming pattern. Global Change Biology, 2006, 12(10): 1969-1976.

[10] Cleland E E, Allen J M, Crimmins T M, Dunne J A, Pau S, Travers S E, Zavaleta E S, Wolkovich E M. Phenological tracking enables positive species responses to climate change. Ecology, 2012, 93(8) : 1765-1771.

[11] 钟波元. 大气和土壤增温对杉木幼苗地上物候、生长和新近光合产物分配的影响 [D]. 福州: 福建师范大学, 2017.

[12］夏富才, 潘春芳, 赵秀海. 温带落叶林的植物物候特征及其对气候变化的响应. 生态环境学报, 2012, 21(5)：793-799.

[13] Augspurger C K. Early spring leaf out enhances growth and survival of saplings in a temperate deciduous forest. Oecologia, 2008, 156 ( 2) : 281-286.

[14] Arend M, Gessler A, Schaub M. The influence of the soil on spring and autumn phenology in European beech. Tree Physiology, 2016, 36( 1) : 7885 .

[15] Fu Y H, Piao S L, Zhou X C, Geng X J, Hao F H, Vitasse Y, Janssens I A. Short photoperiod reduces the temperature sensitivity of leaf-out in saplings of Fagus sylvatica but not in horse chestnut. Global Change Biology, 2019, 25(5) : 1696-1703.

[16] 毛子军, 贾桂梅, 刘林馨, 赵甍. 温度增高、 $\mathrm{CO}_{2}$ 浓度升高、施氮对蒙古栋幼苗非结构碳水化合物积累及其分配的综合影响. 植物生态学 报, 2010,34(10): 1174-1184.

［17］殷晓洁, 周广胜, 隋兴华, 何奇瑾, 李荣平. 蒙古栋地理分布的主导气候因子及其阈值. 生态学报, 2013, 33(1)：103-109.

[18] 韩金生, 赵慧颖, 朱良军, 张远东, 李宗善, 王晓春. 小兴安岭蒙古栋和黄菠萝径向生长对气候变化的响应比较. 应用生态学报, 2019, $30(7): 2218-2230$.

[19] 马立祥, 赵瞢, 毛子军, 刘林馨, 赵溪竹. 不同氮素水平下增温及 $\left[\mathrm{CO}_{2}\right]$ 升高综合作用对蒙古栋幼苗生物量及其分配的影响. 植物生态 学报, $2010,34(3): 279-288$.

[20] 赵娟, 宋媛, 孙涛, 毛子军, 刘传照, 刘林馨, 刘瑞鹏, 侯玲玲, 李兴欢. 红松和蒙古栋种子萌发及幼苗生长对升温与降水综合作用的响 应. 生态学报, 2012, 32(24): 7791-7800

[21] 赵娟, 宋媛, 毛子军. 蒙古栎幼苗光合作用以及叶绿素苂光对温度和降水交互作用的响应. 北京林业大学学报, 2013, 35(1): 64-71.

[22] 延晓冬, 赵士洞, 于振良. 中国东北森林生长演替模拟模型及其在全球变化研究中的应用. 植物生态学报, 2000, 24(1): 1-8.

[23] 郭建平, 高素华, 刘玲, 周广胜. 气候变化对蒙古栋生长和气候生产力的影响. 资源科学, 2005, 27(5): 168-172.

[24] 许中旗, 黄选瑞, 徐成立, 许晴, 纪晓林. 光照条件对蒙古栋幼苗生长及形态特征的影响. 生态学报, 2009, 29(3)：1121-1128.

[25] 李东胜, 白庆红, 李永杰, 许中旗, 于海涛. 光照条件对蒙古栋幼苗生长特性和光合特征的影响. 生态学杂志, 2017, 36 (10)： 2744-2750.

[26] 赵晶. 温度和光照对两种栋属植物幼苗叶形态与结构性状的影响 [D]. 济南: 山东大学, 2013.

[27] 焚后保, 王义弘. 不同光照条件下蒙古栋物候期及树高生长节律的研究. 福建林学院学报, 1992, 12(2)：148-153.

[28］宛敏渭, 刘秀珍. 中国物候观测方法. 北京: 科学出版社, 1979.

[29] 谢芗芗. 中国东部季风主要木本植物萌动及展叶对温度变化的响应 [D]. 北京: 北京林业大学, 2010.

[30］刘斌. 中国北方典型草原植物生殖物候对白天和夜间增温的响应 [D]. 开封: 河南大学, 2015.

[31] CaraDonna P J, Iler A M, Inouye D W. Shifts in flowering phenology reshape a subalpine plant community. Proceedings of the National Academy of Sciences of the United States of America, 2014, 111(13) : 4916-4921.

[32] 张莉, 王根绪, 再飞, 彭阿辉, 肖瑶, 杨阳, 杨燕. 模拟增温改变川西高山草甸优势植物繁殖物候序列特征. 植物生态学报, 2018,42 (1) : 20-27.

[33] Post E S, Pedersen C, Wilmers C C, Forchhammer M C. Phenological sequences reveal aggregate life history response to climatic warming. 
Ecology, 2008, 89(2): 363-370.

[34] 李晓婷, 陈骥, 郭伟. 不同气候类型下植物物候的影响因素综述. 地球环境学报, 2018,9(1): 16-27.

[35] Adams D A, Collins A D, Briggs S P, Vennetier M, Dickman L T, Sevanto S A, Garcia-Forner N, Powers H H, McDowell N G. Experimental drought and heat can delay phenological development and reduce foliar and shoot growth in semiarid trees. Global Change Biology, 2015, 21(11) : 4210-4220.

[36] 胡明新, 周广胜. 拔节期干旱和复水对春玉米物候的影响及其生理生态机制. 生态学报, 2020, 40(1): $274-283$.

[37] Körner C, Basler D. Phenology under global warming. Science, 2010, 327( 5972) : 1461-1462.

[38] Polgar C A, Primack R B. Leaf-out phenology of temperate woody plants : from trees to ecosystems. New Phytologist, 2011, 191(4): 926-941.

[39] Reyer C P O, Leuzinger S, Rammig A, Wolf A, Bartholomeus R P, Bonfante A, de Lorenzi F, Dury M, Gloning P, Jaoudé R A, Klein T, Kuster T M, Martins M, Niedrist G, Riccardi M, Wohlfahrt G, de Angelis P, de Dato G, François L, Menzel A, Pereira M. A plant's perspective of extremes: Terrestrial plant responses to changing climatic variability. Global Change Biology, 2013, 19(1): 75-89.

[40] Fu Y H, Campioli M, Van Oijen M, Deckmyn G, Janssens I A. Bayesian comparison of six different temperature-based budburst models for four temperate tree species. Ecological Modelling, 2012, 230: 92-100.

[41] Fu Y H, Zhao H F, Piao S L, Peaucelle M, Peng S S, Zhou G Y, Ciais P, Huang M T, Menzel A, Peñuelas J, Song Y, Yann V, Zeng Z Z, Janssens I A. Declining global warming effects on the phenology of spring leaf unfolding. Nature, 2015, 526( 7571$)$ : $104-107$.

[42] Fu Y H, Piao S L, Vitasse Y, Zhao H F, De Boeck H J, Liu Q, Yang H, Weber U, Hänninen H, Janssens I A. Increased heat requirement for leaf flushing in temperate woody species over 1980-2012: effects of chilling, precipitation and insolation. Global Change Biology, 2015, 21 ( 7) : 2687-2697.

[43] Asse D, Chuine I, Vitasse Y, Yoccoz N G, Delpierre N, Badeau V, Delestrade A, Randin C F. Warmer winters reduce the advance of tree spring phenology induced by warmer springs in the Alps. Agricultural and Forest Meteorology, 2018, 252: 220- 230. 